\title{
Case of extranodal non-hodgkins lymphoma involving the endometrium and the ovaries: a rare case report
}

\author{
Lakshmi Manjeera Malempati*, Neetha Nandan, Sagarika Babu
}

Department of Obstetrics and Gynecology, K. S. Hegde Medical College, NITTE University, Mangalore, Karnataka, India

Received: 21 June 2017

Accepted: 21 July 2017

*Correspondence:

Dr. Lakshmi Manjeera Malempati,

E-mail: drmanjeera@yahoo.co.in

Copyright: () the author(s), publisher and licensee Medip Academy. This is an open-access article distributed under the terms of the Creative Commons Attribution Non-Commercial License, which permits unrestricted non-commercial use, distribution, and reproduction in any medium, provided the original work is properly cited.

\begin{abstract}
Non-Hodgkin's lymphoma(NHL) is most commonly encountered during childhood and rarely among the adults. Primary malignant lymphoma in the female genital tract are rare Moreover they present with non-specific symptoms and hence there may be delay in the diagnosis. It is difficult to distinguish this condition from the more common uterine neoplasm such as uterine fibroids or sarcoma. Diffuse large B-cell lymphoma (DLBCL) is most commonly seen among the cases of NHL, contributing to among one third of NHL in the western world. DLBCL is common in elderly population. A 69-year-old postmenopausal woman who came with watery discharge since, 15 days was evaluated clinically and radiologically and was found to have thickened endometrium and enlarged ovaries, for which endometrial biopsy was taken that showed non-secretory endometrium with atrophic changes. Tumor markers found to be normal. TAH+BSO was done and the histopathology showed Non-Hodgkin's lymphoma, diffuse large B cell type of the endometrium and both ovaries which was confirmed by immune histochemical marker study. PET-CT was done that showed metabolically active para aortic and common iliac lymph nodes thereby she was diagnosed with stage II (Ann Arbor Staging) non-Hodgkin's lymphoma, hence she received 6 cycles of R-CHOP. As evident in our case, non-Hodgkin's Lymphoma of the endometrium and the ovaries being an extremely rare condition, high-degree of suspicion is required for its prompt diagnosis and treatment.
\end{abstract}

Keywords: Diffuse large B cell lymphoma, Extra nodal lymphoma, Female genital tract, R-CHOP, Non-Hodgkin's lymphoma

\section{INTRODUCTION}

Non-Hodgkin's lymphoma (NHL) is most commonly encountered during childhood and rarely among the adults. Most commonly it involves peripheral lymph nodes, around $15 \% .^{1}$ It can also involve any other organ or tissue and known as extra-nodal NHL.

Primary malignant lymphoma in the female genital tract are rare. Moreover, they present with non-specific symptoms and hence there may be delay in the diagnosis. It is difficult to distinguish this condition from the more common uterine neoplasm such as uterine fibroids or sarcoma. They present with symptoms such as abnormal vaginal bleeding or discharge, pain abdomen, urinary obstruction due to the huge mass

Diffuse large B-cell lymphoma (DLBCL) is most commonly seen among the cases of NHL, contributing to among one third of NHL in the western world. Its estimate being even higher in the developing nation. ${ }^{2}$ DLBCL is common in elderly population. It can involve either the nodal or extra-nodal sites.

Most common extra-nodal involvement is GI tract. Although disseminated involvement of female genital 
tract is not uncommon, primary NHL is rare in this site and usually involves the ovary or uterine cervix. Uterine cervix is the most common primary site in the genital tract and the ovary constitute the secondary site of lymphomatous involvement. ${ }^{3}$ NHL involving the uterus may be either low-stage neoplasm. Ovarian involvement by malignant lymphoma is a well-known late manifestation of disseminated nodal disease. Lymphoma presenting with ovarian mass as an initial presentation is a very rare entity, around $0.3 \%$ and may cause confusion for diagnosis due to its resemblance to much more frequent primary ovarian tumor. ${ }^{4}$

Even once diagnosis is made, owing to its low incidence it poses difficulty to conduct randomized controlled trials, hence there are no standards of treatment. Based on the studies available on treatment of extra-nodal NHL in general, it is suggested that treatment with radiation therapy or surgery combined with chemotherapy improves the outcome. ${ }^{5}$

Here we present a case report on the presentation of nonhodgkin's lymphoma of the uterus and ovary and its diagnosis and treatment.

\section{CASE REPORT}

A 69-year-old postmenopausal woman since, 20 years (Para 2 Living 2) presented to us with the complaints of watery discharge from 15 days, which was on and off, minimal in quantity, not foul smelling and not blood stained. She was a known case of diabetes mellitus, hypertension, bronchial asthma, ischemic heart disease and was on medication. Physical examination and review of systems were unremarkable, except that uterus was bulky on bimanual examination. Pap smear was negative. She underwent abdomen and pelvic ultrasound that revealed uterus normal size and a $2.5 \mathrm{~cm}$ calcified fibroid in the fundus of uterus. Endometrial thickness was $10 \mathrm{~mm}$ with minimal fluid in the cavity. A $45 \times 31 \mathrm{~mm}$ prominent right ovary with few calcifications noted. Left ovary was $55 \times 23 \mathrm{~mm}$ and a cyst measuring $23 \times 28 \mathrm{~mm}$ was noted. No free fluid in POD. No evidence of ascites and lymphadenopathy. In view of this ultrasound report CA125 was done and found to be $33.7 \mathrm{U} / \mathrm{ml}$ which was normal. Inhibin B level, done to rule out granulose cell tumor was $2.27 \mathrm{pg} / \mathrm{ml}$ which was normal.

Endometrial biopsy was done which showed nonsecretory endometrium with atrophic changes. In view of thickened endometrium and bilaterally enlarged ovaries CECT of the abdomen and pelvis was done which showed normal uterus, thickened endometrium. Bilateral bulky ovaries with evidence of thin cyst in the left ovary which measures $3.3 \times 2.8 \mathrm{~cm}$. No lymphadenopathy or ascites and all other organs are found to be normal.

In view of the above findings the possibility of ovarian fibrothecoma was thought of as well as endometriod carcinoma of ovary, though a remote possibility.
In view of the enlarged ovaries, hyperplastic endometrium and the diagnosis being inconclusive she underwent $\mathrm{TAH}$ with $\mathrm{BSO}$. Intra-operative findings revealed uterus corresponding to 8 weeks gravid uterine size with thickened fleshy endometrium on cut section. No growth seen. Bilaterally enlarged ovaries of about $5 \mathrm{x}$ $4 \mathrm{~cm}$ on both sides with unhealthy appearance. All other structures found to be normal. The entire specimen was then sent for histopathological examination.

\section{Pathological findings}

\section{Gross}

Endometrium was markedly thickened and fleshy. Both ovaries were enlarged and measured $3 \mathrm{~cm}$ and $4.2 \mathrm{~cm}$ in diameter each. Cut section of which showed homogenous pale brown and pale-yellow area.

\section{Microscopy}

Multilple sections from body of the uterus showed myometrium with endometrium replaced by tumor tissue made up of groups, sheets and masses of monotonous small round cells having scanty cytoplasm and hyperchromatic nuclei, some with prominent nucleoli. No definite myometrial invasion. Thin walled capillaries were seen. Sections from both the ovaries showed tumor tissue made up of groups, sheets and masses of small round to polygonal neoplastic cells having scanty cytoplasm and round to oval hyperchromatic / vesicular nuclei, some showed prominent nucleoli. Multiple thin walled capillaries were seen.

Histopathology reported features suggestive of nonHodgkin's lymphoma, large cell type of the endometrium and both ovaries, confirmed by Immune histochemical marker study, which showed diffuse large B cell lymphoma of both the uterus and ovary.

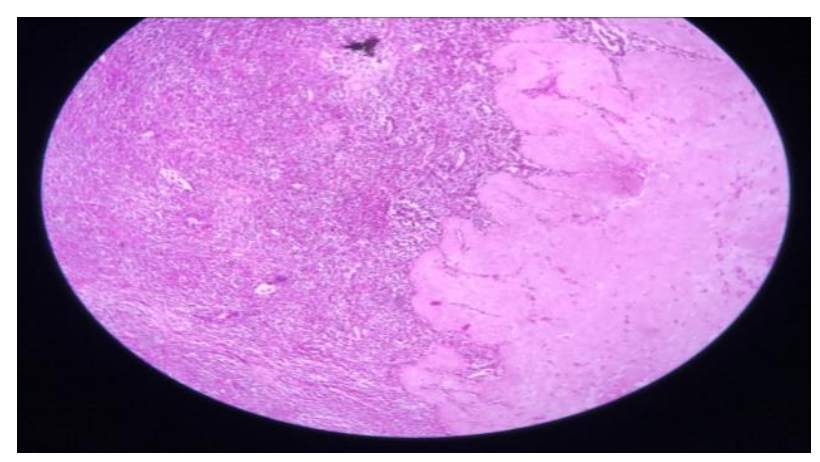

Figure 1: Histopathology of non-hodgkin's lymphoma of the ovary.

As advised by medical oncologist PET CT scan was done from vertex to mid-thigh which revealed metabolically active nodular soft tissue thickening along bilateral pelvic fascia deposits. A confluent metabolically active lymph nodal soft tissue in the aorto caval interval, left para- 
aortic region and along right common iliac vessels measuring altogether $8.1 \times 3.5 \times 3.7 \mathrm{~cm}$. The oncologist reported that the primary being either in the endometrium or the ovaries, the tumor has spread to the common iliac and the para-aortic lymph nodes.

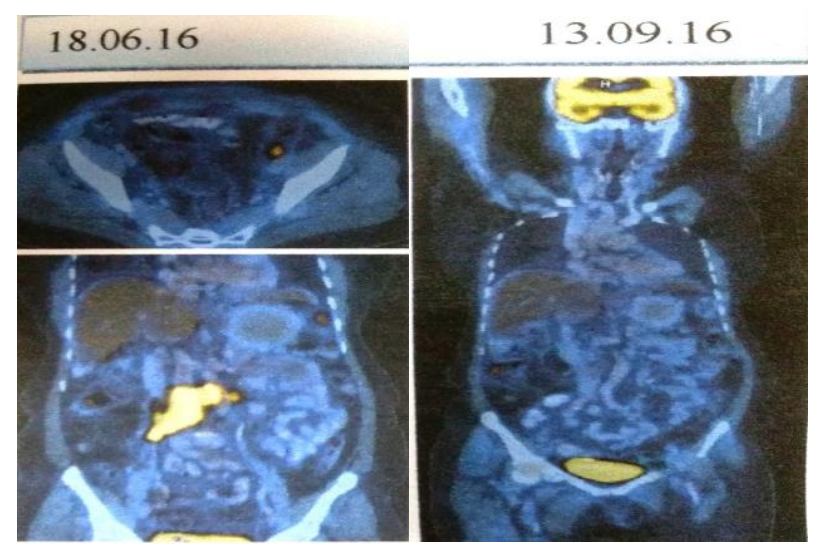

Figure 2: PET CET Scan showing the lesion and the post chemotherapy PET CT Scan showing the regression.

She was hence diagnosed to have Stage II (Ann Arbor Staging) non-hodgkin's lymphoma and she received RCHOP (Rituximab, Cyclophosphomide, Hydroxydaunorubicin, Oncovin and Prednisolone) chemotherapy regimen for 6 cycles. Repeat PET CT scan following chemotherapy showed interval regression of metabolically active lymph nodal soft tissue. There was no evidence of any new lesion. It was considered to have a good response to chemotherapy. She is on regular follow up at present.

\section{DISCUSSION}

In literature, the extranodal NHLs are subdivided into primary and the secondary. ${ }^{6}$ Primary extranodal NHL of the female genital tract is a rare condition accounting for around $2 \%$ of all extranodal lymphomas. ${ }^{7}$ Primary NHL of uterus and cervix is found in around $0.5 \%$ where as extranodal NHL involving uterine corpus and bilateral ovaries are extremely rare like this case. ${ }^{8}$

Primary uterine lymphoma is defined as disease clinically confined to the uterus at initial time of diagnosis, absence of leukemia and at least several months interval between the appearance of secondary site and the primary site. ${ }^{5}$ It is difficult to distinguish between primary and secondary in advanced stage diseases. Likewise, in this case it is difficult to say whether the primary uterine lymphoma metastasized to bilateral ovaries or the uterine lymphoma is secondary to the ovarian primary lymphoma metastatic to uterine body.

Primary NHL involving the female genital tract has been found to have common occurrence around the age of 50 years. As per the review of individual institution databases estimated by Frey et al, primary lymphomas of the uterus and cervix approach a little over half a percent of all extra-nodal NHL, with uterine corpus involvement being the least common site of all. ${ }^{9}$ A clinicopathological analysis of 26 cases of NHL involving the uterus by Vang et al concluded that the prevailing majority are of B-cell lineage with DLBCL being the most common histologic type. $^{6}$

Primary NHL can present with various non-specific clinical manifestations, most common being abnormal uterine bleeding such as menorrhagia, metrorrhagia, irregular menses, post-coital bleeding, post-menopausal bleeding. The severity of this may vary from severe bleeding requiring transfusion, arterial embolization or emergent hysterectomy to being asymptomatic and incidentally diagnosed cases., ${ }^{9,10}$ Other clinical manifestations are abnormal vaginal discharge which our patient has presented with. Asymptomatic cases have been diagnosed incidentally in total abdominal hysterectomy specimens obtained for other conditions or during post-mortem examinations. ${ }^{6}$

Treatment modalities include different combinations of surgery, chemotherapy and radiotherapy. A study of surgical and non-surgical treatment modalities has concluded that more than surgical intervention, its chemotherapy that plays an important role in treating the primary genital lymphomas. ${ }^{11}$ R-CHOP chemotherapy has shown to improve the 5-year survival rates in patients over 60 years of age with diffuse large B-cell lymphoma. ${ }^{12,13}$ Treatment has to be individualized as there are no standard treatment protocols.

Most recent data have shown that NHL involving the rare extra nodal sites including uterus have a poor prognosis with the median overall survival of slightly over 16 months. ${ }^{14}$ A recent analysis of 28 cases of primary malignant lymphoma involving female genital tract showed a 5-year survival rate of $39.3 \% .^{15}$

\section{CONCLUSION}

Non-Hodgkin's Lymphoma of the endometrium and the ovaries being an extremely rare condition, high-degree of suspicion is required for its prompt diagnosis. As evident in our case, the condition presents with non-specific symptoms and even radiology and biopsy finding was noted to be non-characteristic.

Hence, this rare neoplasm need to be kept in the differential diagnosis whenever multiple lesions involving uterus and ovaries are presented, so that it helps in early diagnosis, appropriate management and improve the survival rate.

\author{
Funding: No funding sources \\ Conflict of interest: None declared \\ Ethical approval: Not required
}




\section{REFERENCES}

1. Doren M, Schneider HPG, Holzgreve W. Sonographic manifestation of non-Hodgkin's lymphoma invading the postmenopausal endometrium. Ultra Obstet Gynecol. 1995;6:300-1.

2. Tatishchev S, Lee A, Natural R, Romero JY, Dewar R. Primary diffuse large B-cell lymphoma of the uterus manifesting as a leiomyoma: A unique presentation with review of literature. J Krishna Inst Med Sci Univ. 2013;2:109-16.

3. Srivastava P, Ahluwalia C, Zaheer S, Mandal AK. Primary non-Hodgkin's lymphoma of the female genital tract in a 27-year-old female: A rare case report. Clin Cancer Investig J. 2016;5:287-90.

4. Kaur N, Kaushik R, Gulati A, Kaushal V, Chahal JS. Non-Hodgkin's lymphoma presenting as an ovarian mass. Clin Cancer Investig J. 2014;3:231-4.

5. Yamamoto Y, Chaki O, Nakayama M. Two Cases of NonHodgkin's Lymphoma Involving the Uterus. Gynecol Obstet (Sunnyvale). 2014;4:213.

6. Vang R, Medeiros LJ, Ha CS, Deavers M. NonHodgkin's lymphomas involving the uterus: A clinicopathologic analysis of 26 cases. Mod Pathol. 2000;13:19-28.

7. Shen CJ, Tsai EM, Tsai KB, Wu CH, Hsu SC. Primary T-cell lymphoma of the uterine corpus. Kaohsiung J Med Sci. 2007;23:138-41.

8. Jeong D, Jeong Y, Jeon S, Cho HD, Bae DH, Kim CJ. A case of primary non-Hodgkin's lymphoma of the myometrium with involvement of bilateral ovaries. Basic Appl Pathol. 2009;2:40-3.

9. Frey NV, Svoboda J, Andreadis C, Tsai DE, Schuster SJ, Elstrom R, et al. Primary lymphomas of the cervix and uterus: The University of Pennsylvanias experience and a review of the literature. Leuk Lymphoma. 2006;47(9):1894-901.

10. Bode MK, Tikkakoski T, Johansson J, Johansson K, Kariniemi J, Apaja-Sarkkinen M, et al. Lymphoma of the cervix. Imaging and transcatheter arterial embolization. Acta Radiol. 2002;43(4):431-2.

11. Signorelli M, Maneo A, Cammarota S, Isimbaldi G, Garcia PR, Perego P, et al. Conservative management in primary genital lymphomas: the role of chemotherapy. Gynecol Oncol. 2007;104(2):41621.

12. Feugier $P$, Van Hoof A, Sebban C. Long-term results of the R-CHOP study in the treatment of elderly patients with diffuse large B-cell lymphoma: a study by the Groupe d'Etude des Lymphomes de l'Adulte. J Clin Oncol. 2005;23:4117-26.

13. Niitsu N. Current treatment strategy of diffuse large B-cell lymphomas. Int J Hematol. 2010;92:231-37.

14. Yun J, Kim SJ, Kim JA, Kong JH, Lee SH, Kim K, et al. Clinical features and treatment outcomes of non-Hodgkins lymphomas involving rare extranodal sites: a single-center experience. Acta Haematol 2010;123(1):48-54.

15. Su CF, Tsai HJ, Kuo C, Chen GD, Lin LY, Huang $\mathrm{CC}$, et al. Primary nonHodgkins lymphoma of the uterus, cervix and parametrium treated by combined immunochemotherapy. J Obstet Gynecol Res. 2008; 34(4.2):749-53.

Cite this article as: Malempati LM, Nandan N, Babu

$\mathrm{S}$. Case of extranodal non-hodgkins lymphoma involving the endometrium and the ovaries: a rare case report. Int J Reprod Contracept Obstet Gynecol 2017;6:4131-4. 